\title{
PRODUÇÃO DIDÁTICA EM ÁUDIO E VÍDEO PARA A EAD: RELATO DE EXPERIÊNCIA DO LABORATÓRIO DE EDUCOMUNICAÇÃO DA UNIVERSIDADE FRANCISCANA, SANTA MARIA/RS
}

\author{
SANTA MARIA/RS ABRIL/2018
}

\author{
Taize de Andrade Machado Lopes ～- UFN - prof.taize@gmail.com \\ Tipo: Relato de Experiência Inovadora (EI) \\ Categoria: Suporte e Serviços \\ Setor Educacional: EDUCAÇÃO SUPERIOR
}

\begin{abstract}
RESUMO
A Unidade de Educação a Distância (EAD), da Universidade Franciscana (UFN), é constituída pelos Setores Pedagógico, de Produção de Conteúdos, de Tecnologia Educacional e de Tutoria. A Instituição obteve o credenciamento para oferta de cursos superiores a distância em 2018. Neste trabalho, o objetivo é realizar um relato histórico da criação do Laboratório de Educomunicação (Educom) em 2014, alocado no Setor de Produção, e descrever como se dá o processo para gravação e edição de áudios e vídeos didáticos. A implantação do Educom justifica-se na medida em que áudio e vídeo são recursos pedagógicos eficazes em cursos $E A D$, tornando as aulas mais atrativas para o estudante.
\end{abstract}

Palavras-chave: Educação a Distância. Videoaula. Audioaula. 


\section{Introdução}

A disponibilização de áudio e vídeo em cursos a distância permite a diversificação dos recursos didáticos produzidos e ofertados ao estudante. Além disso, tornam as aulas mais atrativas, potencializando a aprendizagem. De acordo com Bahia e Silva (2017, p. 4), a linguagem audiovisual pode proporcionar a aproximação do discente com o "mundo tangível ou figurável", se utilizada consistente e adequadamente, "[...] pois permite que este se perceba implicado no conteúdo abordado, promovendo a reflexão e o pensamento crítico".

Para dar suporte à produção de materiais audiovisuais na EAD da Universidade Franciscana (UFN), foi criado o Laboratório de Educomunicação (Educom), ligado ao Setor de Produção, que conta com equipe especializada. Essa equipe é constituída de profissionais da área de Comunicação Social (Jornalismo, Relações Públicas e Publicidade e Propaganda), além de contar com o suporte da TV e Rádio da instituição.

A Universidade Franciscana obteve recentemente o credenciamento institucional para oferta de cursos superiores a distância (março/2018) e, também, o credenciamento como universidade (outrora, centro universitário). A UFN localiza-se em Santa Maria/RS, possui trinta e quatro cursos de graduação, seis mestrados e dois doutorados, totalizando mais de 6.000 alunos. É uma instituição comunitária, filantrópica, de direito privado e sem fins lucrativos.

A caminhada da Educação a Distância na instituição começou em 2013, em consonância com o Plano de Desenvolvimento Institucional (PDI), a partir da constituição de uma equipe para a gestão do credenciamento para a oferta de cursos superiores EAD. Entretanto, a partir de 2010, os primeiros esforços para esse credenciamento já haviam sido realizados. Foi criado o Espaço Virtual de Aprendizagem Mais Unifra, um repositório de conteúdos digitais e objetos de aprendizagem produzidos pelos docentes da Universidade, fruto do conhecimento adquirido pelos professores da IES, a partir da participação no projeto Rede Interativa Virtual de Educação (RIVED).

Em 2011 foi criada a Unidade de EAD e a partir de 2013, passou-se a criar e executar o projeto de credenciamento em Educação a Distância, com a constituição de equipe de professores conteudistas, tutores, técnicos-administrativos e a criação de curso superior na modalidade EAD para avaliação do Ministério da Educação. Nesse período, também houve a constituição de oito polos presenciais. Os polos da UFN situam-se em Brasília/DF, Dourados/MS, Guaíra/PR e, no Rio Grande do Sul, em Bagé, Canguçu, Cruz Alta, Pelotas e Santa Maria. 
Em 2015, as visitas dos avaliadores do Ministério da Educação tiveram início, sendo finalizadas em março de 2017, com a avaliação do polo de Brasília. Os conceitos obtidos nas avaliações situaram-se entre 4 e 5 , tanto para os polos e sede, quanto para o Curso Superior de Tecnologia em Gestão de Recursos Humanos (CSTGRH).

Neste relato de experiência será descrito como ocorre a gravação, edição e publicação de materiais didáticos em áudio e vídeo na EAD da Universidade Franciscana. A Unidade de EAD da IES prima tanto pela produção de objetos de aprendizagem, quanto pela disponibilização de áudios e vídeos, além dos textos e exercícios tradicionalmente disponibilizados ao estudante no Ambiente Virtual de Aprendizagem (AVA).

\section{Produção de materiais didáticos para modalidade de Educação a Distância: áudio e vídeo}

Diversificar os materiais disponibilizados para o estudante da modalidade de Educação a Distância tem sido um dos objetivos da Unidade de Educação a Distância da Universidade Franciscana. Neste contexto, entende-se que apresentar conteúdos didáticos em áudio e vídeo é considerado uma forma atrativa e eficaz de disponibilização de recursos educacionais digitais.

Para Souza (2016, p. 24), gravações em áudio e vídeo "[...] podem ser usadas para explicar conteúdos ou passagens do texto didático, demonstrar instruções de uso sobre algo, ensinar procedimentos diversos, apresentar opiniões de especialistas, entre outras funções".

No entanto, para que tenham qualidade, as gravações em áudio e vídeo requerem planejamento, recursos humanos e técnicos, que possuem alto custo e tempo para produção, não estando ao alcance de muitas IES (SOUZA, 2016). Nesse cenário, Bahia e Silva (2017) explicam que a construção de um vídeo com fins didáticos demanda parceria do docente, que é especialista no assunto e a equipe de produção de materiais.

Nesse contexto, o Laboratório de Educomunicação (Educom) foi implantado com objetivo de realizar a gestão da produção de material didático em áudio e vídeo e é constituído por profissionais da área de Comunicação Social, com suporte da TV e Rádio da UFN. A edição é feita na Unidade de EAD por um profissional de Publicidade e Propaganda especializado no conhecimento em produção audiovisual.

A necessidade da criação do Educom emergiu em 2014, quando houve demanda por gravação de videoaulas para o Curso Superior de Tecnologia em Gestão de Recursos 
Humanos (CSTGRH), que naquele momento, estava sendo elaborado para obtenção do credenciamento institucional em EAD. Verificou-se que seria necessário suporte para os docentes conteudistas, constituindo-se não só da gravação em si, mas também de capacitação técnica desses professores para lidarem com a linguagem específica. Desta forma, ficou sob responsabilidade do Educom cursos de formação para os docentes envolvidos na criação do CSTGRH, a criação do cenário da EAD no estúdio da UFN TV e o formato dos materiais didáticos em áudio e vídeo.

Observa-se, a partir do contexto descrito acima, que para a materialização dos produtos didáticos planejados pelos professores conteudistas na Educação a Distância, é imprescindível a manutenção de uma equipe multidisciplinar de apoio. Os Referenciais de Qualidade para Educação Superior a Distância (MEC, 2007, p. 13) já traziam essa preocupação ao afirmar que "cabe observar que somente a experiência com cursos presenciais não é suficiente para assegurar a qualidade da produção de materiais adequados para a educação a distância". Assim, para a produção de materiais didáticos para EAD é importante que os professores conteudistas trabalhem integrados a uma equipe multidisciplinar.

Nesse sentido, é fundamental o investimento institucional em uma equipe capacitada e em professores conteudistas engajados com o projeto. Dessa forma, convencidos que diversificar os materiais disponibilizados ao estudante torna um curso mais atrativo, a Universidade Franciscana implantou o Laboratório de Educomunicação, potencializando, inclusive, um novo espaço de formação para os estudantes dos cursos de Jornalismo e Publicidade e Propaganda da UFN.

\section{Produção de materiais didáticos em áudio e vídeo na EAD da Universidade Franciscana: capacitações, roteiros e gravações}

\subsection{Criação do Laboratório de Educomunicação e capacitações realizadas}

Como descrito anteriormente, o Laboratório de Educomunicação (Educom) foi criado em 2014, integrando-se ao Setor de Produção e dentre as primeiras demandas estava a padronização do figurino utilizado pelos professores conteudistas.

Além disso, em 2014 também foram realizadas capacitações para os docentes do CSTGRH sobre roteirização de conteúdos, técnicas de locução e posicionamento frente às câmeras. Ocorreram outras capacitações específicas para novos grupos nos anos seguintes e, em 2017, foi realizado o curso de extensão Alta Performance para Professores na Educação a Distância. 
Nesse curso, foram abertas 17 vagas para docentes da modalidade presencial da UFN, que tivessem interesse em produção de materiais didáticos no formato audiovisual. Foram compartilhadas técnicas para locução e gravação desses materiais, tanto na Rádio quanto na TV. Nessa capacitação, os inscritos puderam produzir seus próprios materiais, em áudio ou vídeo, conforme sua escolha. Esses produtos podem ser usados como apoio às aulas presenciais e disponibilizados no AVA pelo professor.

\subsection{Gravações de áudio e vídeo educacionais: produção, edição e publicação}

As atividades do Laboratório de Educomunicação, o Educom, estão diretamente ligadas ao trabalho desenvolvido no Setor Pedagógico, responsável pelo atendimento ao professor conteudista. Esse, a partir do acompanhamento de um orientador pedagógico, estabelece dentro do seu plano de aprendizagem quais conteúdos serão produzidos na modalidade de áudio ou vídeo. O cuidado nesse momento é a orientação ao professor conteudista para que entenda as possibilidades do uso de áudio e vídeo nas aulas, considerando as particularidades do consumo que o público (no caso alunos) faz desse tipo de material.

Principalmente, no que se refere à EAD, Santos et al (2006, p. 5) explicam que "nessa modalidade, se considera que a interlocução entre o professor e o estudante não ocorre necessariamente num mesmo tempo e/ou espaço. Portanto, o processo educativo é precedido de um rigoroso planejamento, principalmente na elaboração do material didático".

Nesse sentido, o áudio, segundo Sampaio (1995, p.80), é tido como "uma excelente opção como mídia dirigida", uma vez que instiga a imaginação das situações descritas e pode ser específica para cada público. Exige atenção de apenas um dos sentidos humanos, a audição, e ao mesmo tempo é possível tomar contato com o conteúdo enquanto se executa alguma tarefa corriqueira, o que pode ser uma vantagem. Porém, esse tipo de material não é recomendado para situações em que o conteúdo exija explicações complexas ou muito prolongadas. Já o audiovisual, para Sampaio (1995, p.79), causa maior impacto por ser mais completo: "o uso de mensagens com som, imagem, cores e movimentos", mas, por outro lado, exige atenção exclusiva, uma vez que a mensagem é transmitida a partir da visão e da audição.

Portanto, definidos os conteúdos a serem trabalhados e o formato que o material terá usando apenas o áudio (audioaula, entrevista, radionovela, jingle, podcast, etc.) ou também o vídeo (videoaula, entrevista, reportagem, screencast, etc.) - o próximo passo é a construção do roteiro que guiará a produção do material. É a confecção do roteiro 
que exigirá do professor conteudista e do orientador pedagógico a maior dedicação em termos de detalhamento do que será realizado e como deverá ser realizado. Cada informação deverá estar contextualizada quanto à sonorização, se é um material em áudio (por exemplo ao estabelecer se vai ser gravada só a voz do professor, se terá som de fundo, trilha sonora, etc.) ou quanto à imagem, se é material em áudio e vídeo (por exemplo informando a imagem que estará na tela e o som que será executado em cada momento do vídeo).

No que se refere a elaboração de um roteiro adequado, Bahia e Silva (2017, p. 8) explicam que o docente, ao planejar a aula, deve responder questões como "[...] quem é o estudante? Quais aspectos do conteúdo podem sensibilizar e despertar seu interesse? Que relações podem ser estabelecidas entre o conteúdo e a realidade do estudante? De que maneira esse conteúdo pode ter impacto positivo na vida do estudante? [...]". É pensando nestas questões, que o docente terá um norte para a escolha do conteúdo, cenário, linguagem, entre outros.

Estabelecido o roteiro, que ainda passa por revisão no Setor de Produção, a sequência do processo se dá no agendamento do estúdio de gravação (estúdio de Rádio ou de TV), no agendamento do professor e/ou convidado e nas orientações para que os mesmos tenham a melhor atuação frente aos microfones e/ou câmeras. Orientações essas imprescindíveis para que o esforço comunicativo dos envolvidos tenha êxito na finalização de um material de alta qualidade. Na gravação de material em áudio, é dada atenção especial para a expressividade oral de quem irá gravar, considerando a ênfase, pausas e velocidade de fala, entre outros aspectos. Já no audiovisual, a atenção inicia com os cuidados desde as vestimentas e acessórios, com orientação para o tipo de roupa e as cores que tenham melhor efeito no vídeo. Também, recomenda-se aos professores que as videoaulas não ultrapassem cinco minutos de duração. Essa duração máxima é corroborada por Bahia e Silva (2017, p. 4), que afirmam "[...] que a atenção do aluno perdura de modo satisfatório para a aprendizagem no tempo médio de 3-5min., podendo, conforme didática, estender-se até 8 minutos".

No caso de conteúdos em áudio, aceita-se uma duração maior, principalmente se forem gravados como debates ou entrevistas. Entretanto, não é recomendado aos professores que esses materiais excedam mais do que vinte minutos de duração.

O momento de gravação, conforme material a ser confeccionado, não exige, em geral, muito tempo do professor e/ou convidado, considerando que o conteúdo foi previamente repassado e está bem absorvido. Após esse momento, o trabalho fica por conta do produtor do Educom que irá editar o material que foi gravado em pequenos módulos, 
montando o produto final a ser disponibilizado para aprovação da equipe pedagógica. Os materiais são posteriormente disponibilizados no AVA, organizados conforme o plano de aprendizagem do professor.

Atualmente, a Unidade de EAD, através do Educom, já produziu mais de 140 materiais entre audioaulas, videoaulas e screencasts. Esses são utilizados para atividades no ambiente virtual, como apoio às disciplinas presenciais, ou como material para os cursos na modalidade de Educação a Distância que serão oferecidos pela Instituição.

\section{Considerações finais}

Tendo início com o Espaço Virtual de Aprendizagem Mais Unifra, a Unidade de Educação a Distância da Universidade Franciscana foi criada em 2011. A partir do processo de credenciamento em EAD e da demanda por gravações de videoaulas do primeiro curso de graduação na modalidade a distância, à Unidade foram agregando-se uma equipe de professores conteudistas, tutores, técnicos-administrativos e, posteriormente, uma equipe de profissionais da área da comunicação, que levou à criação do Laboratório de Educomunicação, o Educom, em 2014. O credenciamento institucional para oferta de cursos superiores em EAD foi obtido em março de 2018.

Responsável pela gestão da produção de material didático em áudio e vídeo, o Educom conta com o suporte da TV e Rádio da UFN. A produção está vinculada ao trabalho do Setor Pedagógico que orienta o professor conteudista para a confecção do roteiro, que posteriormente é encaminhado para o Setor de Produção. Na sequência são feitos os contatos de reserva dos estúdios e dos docentes envolvidos nas gravações, os quais são orientados para que tirem o melhor proveito do material a ser produzido. Após, a gravação e edição dos produtos em audiovisual, o processo de produção é finalizado e as audioaulas, videoaulas ou screencast são encaminhadas para aprovação e publicação no AVA.

Nesse sentido, o Laboratório de Educomunicação passou a ser uma necessidade, visto que agrega qualidade ao material de áudio e vídeo produzidos. O trabalho vai desde as orientações aos professores e convidados no que diz respeito ao uso adequado da voz e da imagem, até aos cuidados de gravação e edição, para que o produto resultante apresente um alto desempenho e cause impacto positivo no estudante, potencializando o processo de ensino-aprendizagem.

\section{Referências}


BAHIA, Ana Beatriz; SILVA, Andreza Regina Lopes da. Modelo de produção de vídeo didático para EaD. Revista Novas Tecnologias na Educação. v. 15, n. 1, 2017.

MINISTÉRIO DA EDUCAÇÃO - MEC. Referenciais de Qualidade para Educação Superior a Distância. Brasília, 2007. Disponível em: Acesso em 25.04.2018.

SAMPAIO, Rafael. Propaganda de A a Z: como usar a propaganda para construir marcas e empresas de sucesso. Rio de Janeiro: Campus, 1995.

SANTOS, Cleusa Ribeiro dos; ZANETTE, Elisa Netto; NICOLEIT, Graziela Fátima Giacomazzo; FIUZA, Patrícia Jantsch. A construção do material didático para a Educação a Distância: a experiência do setor de Educação a Distância da UNESC. Revista Novas Tecnologias na Educação. v. 4, no 1, jul. 2006.

SOUZA, Renato Antonio de. Multimídia no EaD. São Paulo: Cengage, 2016. 